\title{
ПРОБЛЕМА ОБЕСПЕЧЕНИЯ БЕЗОПАСНОСТИ КАК ПРЕДПОСЫЛКА ФОРМИРОВАНИЯ МИРОВОГО ГОСУДАРСТВА
}

\begin{abstract}
Аннотация: В статье исследуются проявления современных проблем связанных с обеспечением безопасности внутри государства и на международном уровне. На примере рассмотрения конфликтов современности делается анализ проблем их политико-правового регулирования и выясняется возможность их разрешения с помощью существующей системы соииального управления. Раскрываются такие вопросы как допустимость вмешательства государства в дела других государств, проблема бесконтрольности производства и использования оружия массового поражения, а также международного терроризма. В заключении исследования делается вывод о том, что современные международные и национальные институты показывают несостоятельность в обеспечении безопасности человека, что приводит к необходимости создания в будущем нового типа объединения в границах всего человечества.
\end{abstract}

Ключевые слова: Юриспруденция, глобализация, политика, мировой, государство, война, оружие, безопасность, США, $\mathrm{OOH}$

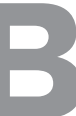

современности остро стоит вопрос обеспечения безопасности человека и решения проблемы ее политико-правового регулирования. Как в международных отношениях, так и внутри государств отсутствуют механизмы, которые в необходимой степени могли бы гарантировать стабильность общественных отношений и сохранение правопорядка. Под безопасностью традиционно понимается такое состояние, при котором никакое внутреннее или внешнее воздействие на систему не ведет к ее разрушению или утрате каких-либо функций. Безопасность человека представляет такое состояние, при котором внешние и внутренние воздействия не приводят к ухудшению функционирования организма, создания, психики или смерти, а также не затрудняет достижения человеком его целей.Таким образом, все существующие внешние или внутренние факторы так или иначе способны влиять на безопасность человека. Другими словами только выживание и стабильное существование дает возможность для появления других целеполаганий. Хотя социальная составляющая человека делает его человеком, биологический компонент является первичным. Человек может прожить без общества гораздо больше, чем он сможет прожить без еды или воды. Безопасность, несмотря на то, что является уже юридическим понятием, характеризует именно биологическое состояние человека, жизнь, здоровье, свободу, состояние психики.
Проблемы безопасности были всегда одними из ключевых, с их решением было связано создание необходимых условий для жизнедеятельности людей, удовлетворения их потребностей и интересов, а в XX столетии - и само существование человечества ${ }^{1}$. Именно в обеспечении мира и безопасности, как указывает Р. Паунд заключается основная цель права². Потому функция безопасности в современном мире выходит на первое место и предопределяет взвешенную общемировую, а также локальную политику отдельных регионов ${ }^{3}$.

Анализируя внешнюю сторону безопасности человека (безопасность государств в разрезе военных конфликтов) в стратегическом плане с точки зрения глобальных тенденций правомерно говорить

\footnotetext{
${ }^{1}$ См.: Гнатик E.H. К проблеме наукоемкого терроризма в глобализующем мире // Глобализация и проблема сохранения культурного многообразия. С. 76; Макарычев А.С. Международное сообщество, глобализация и безопасность / Международное сообщество и глобализация угроз безопасности: сб. науч. докладов. Ч. 2. Международное сообщество и национальные государства в поиске ответов на новые угрозы безопасности / отв. ред. В.В. Грохотова, Б.Н. Ковалев, Е.А.Макарова. В. Новгород, 2008. С. 21; Маркушина Н.Ю. Международные организации - арена сотрудничества или дружбы России и США? / Международное сообщество и глобализация угроз безопасности. С. 59.

${ }^{2}$ Pound $R$. The ideal element in law. Indianapolis, 2002.P. 144-146.

${ }^{3}$ НовиковА.А. Планетарное государство - глобальная экономическая и социальная модель. - М., 2008.С. 24.
} 
об относительном уменьшении роли военной силы. Но использование этого инструментария в реальной практике отнюдь не уходит в прошлое и не исключено, что его применение может стать более широким по территориальному ареалу. Проблема видится в том, что использование военной силы может быть обусловлено обеспечением максимального результата в кратчайшие сроки при минимизации политических издержек - внутренних и внешних ${ }^{4}$. Проблемные ситуации внутри государств (этноконфессиональные, связанные с сепаратизмом, миграционными и демографическими процессами, коллапсом государственных структур) становится труднее удержать во внутреннем вакууме. Они влияют на отношения с другими странами, затрагивают их интересы, сказываются на состоянии мировой системы в целом. Отсюда возникает следующий вопрос. Каким представляется допустимым воздействие на внутриполитические ситуации в тех или иных странах, а также его цели, средства и пределы 5 ?

Ярким примером указанной политико-правовой дилеммы является ситуация, возникшая в Ливии в марте-апреле 2011 года, когда гражданско-политические противоречия выросли в гражданскую войну, при которой действующая власть использовала военную силу для подавления восстаний, в том числе убивало представителей оппозиционного движения. В соответствии с принятой в ночь на 18 марта 2011 года резолюцией Совета безопасности ООН, международное сообщество ввело над страной бесполетные зоны над Ливией, чтобы правительство больше не могло использовать против повстанцев авиацию. Кроме того, резолюция разрешала любые меры воздействия для защиты гражданского населения от сил ливийского лидера, за исключением иностранной оккупации. В ответ на резолюцию правительство объявило о прекращении всех военных действий против повстанцев, а также пригласило международных наблюдателей следить за соблюдением перемирия. Однако столкновения в Ливии продолжались вплоть до конца мая 2011 года.

В этой ситуации традиция «вестфальского» подхода к международно-политической системе о недопустимости вовлечения во внутриполитические дела государств и максимально ограниченной трактовки оснований и пределов вмешательства противосто-

\footnotetext{
${ }^{4}$ Современные глобальные проблемы: учеб. пособие / ред. А.С. Дундич. М., 2010. С. 39.

${ }^{5}$ Современные глобальные проблемы. С. 41.
}

яла необходимости реагирования международного сообщества на колоссально большое количество насилия, убийств и грубых нарушений прав и свобод человека и гражданина на территории Ливии. В результате фактическое вмешательство (на первой стадии США, Франции, Италии и других государств и в дальнейшем НАТО) абсолютно превысило допустимые в международных отношениях пределы вмешательства во внутренние политические дела государства, что вызвало неоднозначную реакцию со стороны международного сообщества. Ситуация в Ливии продемонстрировала, что степень влияния международного сообщества не просто ограничивается общегосударственными интересами, но и позволяет ему влиять и даже изменять внутригосударственный строй государства, в случае если действия правящей власти не соответствуют общепризнанным правовым стандартам.

В научной литературе ни раз высказывалась точка зрения, согласно которой в случае если нарушаются основополагающие права и свободы человека и гражданина, то вопрос суверенитета и возможного вмешательства не должен стоять перед международным сообществом ${ }^{6}$.Международное сообщество допускает в исключительных случаях использование вооруженной силы для прекращения систематических нарушений прав человека7 ${ }^{7}$ П. А. Кропоткин в этой связи писал, что для всякой революции необходимо ощущение недовольства настоящим, осознание безысходности положения, непоправимости его обычным путем, а также готовность пойти на риск, чтобы изменить это положение ${ }^{8}$. Кроме того, это обосновывается и классической естественно-правовой теорией, согласно которой с целью сохранения своих естественных прав, народ сохраняет за собой право на восстание9. В случае если правительство перестает защищать основополагающие права и свободы и более не преследует цели общего благосостояния люди полностью правомочны отозвать его ${ }^{10}$.

\footnotetext{
${ }^{6}$ Beetham D., Boyle K. Introducing democracy: 80 questions and answers. PolicyPress, 1995. P.128.

${ }^{7}$ Грохотова В.В. Развитие доктрины «гуманитарной интервенции» в международном праве / Международное сообщество и глобализация угроз безопасности. С. 26.

${ }^{8}$ Канев С.Н. Революция и анархизм: Из истории борьбы революционных демократов и большевиков против анархизма (1840-1917). M., 1987.C. 200.

${ }^{9}$ Locke J. Two Treatises of Government. Cambridge,1988. P. 124.

${ }^{10}$ Becker $C$. The Declaration of Independence: A Study in the History of Political Ideas. N.Y., 1922. ch.1.
} 


\section{Национальная безопасность 2(25) • 2013}

Вместе с тем, скептически анализируя сложившиеся международные противоречия, можно представить несколько другую гипотетическую ситуацию, которая ставит под сомнение реальность действия принципов, закрепляемых в статье 2 Устава $\mathrm{OOH}$, в том числе: суверенного равенства государства, невмешательства в дела, входящих во внутреннюю компетенцию государств, нерушимости государственных границ, территориальной целостности государств. Если одно государство, каким-либо образом (финансовыми или политическими методами) заставит определенную группу в другом государстве выступить как крайне оппозиционную силу, требующую устранения действующего политического строя, то очевидно, что этим государством будут предприняты меры для подавления экстремистского движения. Оценка предпринятых мер ложится на международное сообщество, а в рассматриваемом случае на лиц, принявших решение в Совете Безопасности ООН. Данная оценка членов международного сообщества в любом случае будет отталкиваться исходя из национальных интересов стран, а потому не может быть во всех случаях объективной, несмотря на наличие или отсутствие доказательств нарушения основополагающих прав и свобод граждан, проживающих на территории государства, где происходит конфликт.

Для решения указанной проблемы были озвучены следующие предложения: внести поправки в Устав $\mathrm{OOH}$, создать специальный международный договор, принять резолюцию Генеральной Ассамблеи $\mathrm{OOH}^{11}$. В качестве критериев допустимости международной интервенции указываются: справедливое дело: крупномасштабные человеческие жертвы, связанные с геноцидом, этническими чистками и другими преступлениями; благое намерение: предотвращение страданий людей; последнее средство: другие средства мирного разрешения конфликта исчерпаны; соразмерность военного вмешательства целям и обстановке; вероятность успеха проводимой интервенции ${ }^{12}$.

Вместе с тем, даже введение подобного рода критериев не позволяет разрешить возникающий конфликт интересов международных органов, государств являющихся их членами и третьих государств. Так как критерии гуманистической целесообразности впадают в противоречие с критериями эко-

\footnotetext{
${ }^{11}$ Грохотова В.В. Указ. соч. С. 28

${ }^{12}$ Грохотова В.В. Указ. соч. С. 33.
}

номической и политической полезности. При этом современная система международного права и «национальных» государств только закрепляет систему политических войн, а не видоизменяет ее в механизм предотвращения и разрешения конфликтов.

Существенно усугубляет указанные противоречия развитие оружия массового поражения ${ }^{13}$. Несмотря на очевидную важность поддержания баланса и минимизации оружия массового поражения, государства не всегда следуют всеобщим интересам. В настоящее время военная промышленность только распространяется ${ }^{14}$.Н. Ф. Федоров отметил: «Адская технология, производящая орудия истребления для оправдания своего существования, хочет видеть в крайней истребительности своих орудий сильнейшее средство против войны, т.е. хочет уверить в этом всех, забывая или скрывая при этом, что вооруженное состояние, постоянное ожидание войны не лучше, если не хуже самой войны»

Например, некоторые важные соглашения между США и Россией перестали действовать, а заключение других оказалось под вопросом ${ }^{16}$. Среди них Договор «Об ограничении систем противоракетной обороны» 1972 года, Договор «О запрещении ракет средней и меньшей дальности (РСМД)» 1987 года, Два договора о сокращении стратегических наступательных вооружений (СНВ-1 1991 года и СНВ-2 1993 года) и Договор «О сокращении стратегических наступательных потенциалов» (СНП, или Московский договор) от 2002 года ${ }^{17}$.

В целом режимы соблюдения международного ядерного нераспространения испытывали серьезное давление. В 2004 году из Договора о нераспространении ядерного оружия вышла КНДР, которая провела ядерные испытания в 2006 и 2009 году и стала первым государством - участником Договора, вышедшим из него. Пхеньян тайно осуществлял запрещенные операции по производству оружейных материалов и когда эта деятельность была обнаружена, Северная Корея заявила о выходе из Договора, что создало опасный прецедент для ряда других стран.

\footnotetext{
${ }^{13}$ Гезалов А.А. Трансформация общества в эпоху глобализации: Социально-философский анализ. М., 2009. С.85-86.

${ }^{14}$ Глобальные трансформации: Политика, экономика, культура / Д. Хелд, Д. Гольдблатт, Э. Макгрю и др. М., 2004. С. 143.

15 Федоров Н.Ф. Философия общего дела: Статьи, мысли и письма. Т.1. Верный, 1906. С. 663.

${ }^{16}$ Глобальные конфликты нового и новейшего времени: учеб. пособие / ред. Н.В. Паниной. М., 2005. С. 109

${ }_{17}$ Современные глобальные проблемы. С. 44.
} 
В итоге возникает ситуация, когда развивающиеся страны пытаются противостоять мировым державам, а последние пытаются не допустить поднятия их технологического уровня до ситуации, когда они смогут оказывать существенное воздействие на политику и экономику ${ }^{18}$.Такую ситуацию можно было наблюдать в 2008-2011 гг. в отношении Ирана, когда Евросоюз и США были вынуждены применять санкции из-за необходимости сдерживания ядерного роста неподконтрольного им государства, который с 2005 года стал осуществлять масштабную программу обогащения урана. С 2006 года Совет Безопасности ООН принял шесть резолюций с призывами к Ирану прекратить обогащение урана и выполнить все требования МАГАТЭ. В дальнейшем были введены санкции в виде запретов на продажу Ирану товаров и технологий, пригодных для использования в ядерной программе, замораживании счетов лиц и организаций, причастных к ядерной программе, ограничении экспорта и импорта вооружений ${ }^{19}$. Однако, «ядерные разногласия» касаются не только Ирана, но также и Северной Кореи, Пакистана, Индии.Каждое расширение «ядерного клуба» оборачивается для международно-политической системы тяжелейшим стрессом, в то время как стимулом для расширения становится факт сохранения ядерного оружия крупнейшими странами в качестве средства обеспечения безопасности ${ }^{20}$.

Кроме того, процесс создания ядерного вооружения является дорогим и сложным процессом, что делает недоступными данные средства массового поражения для небольших политических образований, а также террористических групп ${ }^{21}$. Но при возрастании информационной и рыночной доступности, возрастает риск распространения данного вооружения. По оценкам МАГАТЭ, более 30 стран имеют технологическую возможность для разработки ядерного оружия $^{22}$, и с развитием технологического прогресса эта цифра будет только расти. Как справедливо указывается С. С. Веселовским в отношении владения ядерным оружием террористическими группами,

\footnotetext{
${ }^{18}$ Boswell T. Hegemony and Bifurcation Points in World History // The Future of Global Conflict. L., 1999. P. 282.

${ }^{19}$ Современные глобальные проблемы. С.142.

${ }^{20}$ Современные глобальные проблемы. С. 40.

${ }^{21}$ Современные глобальные проблемы. С. 51.

22 Фельдман Д.М. Россия перед будущими международными конфликтами // Власть. 2007. № 12. С. 75-79.
}

ситуация усугубляется тем, что они неподконтрольны международному законодательству и не имеют «обратного адреса», на который можно было бы произвести вооруженный ответ ${ }^{23}$. Кроме того, если для стран ядерное оружие является стратегически сдерживающим фактором ${ }^{24}$, то при обладании им террористическими группами, оно с высокой долей вероятности будет применено.

В. Г. Барановскийзамечает, что «серьезную проблему для поддержания международных режимов нераспространения представляет технологический дуализм мирной атомной энергетики и военных программ по созданию ядерного оружия...... Производство топлива для АЭС основано на обогащении природного урана до уровня $5 \%$. Однако те же технологии можно применять и для дальнейшего обогащения этого материала с целью производства оружейного урана (уровень обогащения свыше 90\%)»². Ядерное вооружение при этом тесно связано с разветвленной системой командования и управления, состоящей из устойчивых к ядерному удару командных центров (могут находится также на воздушном или морском судне), радаров, спутников, средств связи и компьютеров ${ }^{26}$. Их задачей является предупреждение о возможной атаке и гарантирование, что силы возмездия будут способны выполнить свою миссию, даже «пережив» ядерный удар ${ }^{27}$.

Мартин Ван Кревельд рассматривая проблемы связанные с ядерным вооружением обращает внимание на несколько другую особенность и роль оружия массового поражения. Появление ядерного оружия, пишет ученый, привело к другой тенденции - демилитаризации государств. В 1941 году во вторжении немцев в СССР, крупнейшей военной операции за всю историю, были задействованы 144 дивизии из примерно 209, имевшихся в распоряжении вермахта ${ }^{28}$. После 1945 года ни одна военная операция на Земле не насчитывала более 20 полных дивизий в одной компании ${ }^{29}$. К концу 90-х гг. армии только двух государств, Китая и Индии, превышали 1,5 млн человек

\footnotetext{
${ }^{23}$ Современные глобальные проблемы. С. 174.

${ }^{24}$ См.: Мунтян М.А. Иммануил Кант и теория всеобщего мира. C. $39-85$.

${ }^{25}$ Современные глобальные проблемы. С. 56.

${ }^{26}$ Bracken P. The Command and Control of Nuclear Forces. New Haven, 1983.

${ }^{27}$ Кревельд М. Расцвет и упадок государства. М., 2006. С. 418.

${ }^{28}$ Кревельд М. Расцвет и упадок государства. С. 423.

${ }^{29}$ Кревельд М. Расцвет и упадок государства. С. 424.
} 


\section{Национальная безопасность 2(25) • 2013}

(а в 1945 году только в США под ружьем находилось 12 млн человек). Значительно сократились основные виды оружия и системы вооружения. На конец 1945 года США выпускали в среднем 75000 военных самолетов ежегодно, когда в начале XXI века США приобретается не более 200 летательных аппаратов в год. Количество авианосцев с одной сотни в 1945 году снизилось до одного десятка к 2012 году. Такое положение дел характерно и для других стран.

Отчасти это обусловлено и разницей в цене вооружения. Если раньше стоимость одного военного самолета примерно была равна 50000 долларов США, то сейчас стоимость истребителя (например, F 15I) может доходить до рекордной суммы в 100000000 долларов США ${ }^{30}$.Но главной причиной сокращения вооружения, конечно же, является наличие действительного и действующего ядерного вооружения с необходимыми средствами доставки и точностью радиуса поражения. Указанная тенденция безусловно свидетельствует о качественном изменении военно-политических отношений на мировой арене.

Однако ядерное оружие не является единственным краеугольным камнем. Отсутствуют необходимые методы контроля и в отношении химического и биологического оружия. Химическое оружие запрещено в соответствии с Конвенцией «О запрещении химического оружия» (КХО) 1997 года, а биологическое и токсическое - Конвенцией «О запрещении биологического и токсического оружия» (КБТО) 1972 года. Если за соблюдением КХО следит Организация по запрещению химического оружия (ОЗХО) со штаб-квартирой в Гааге (Нидерланды), то КБТО не располагает органом по мониторингу за ее соблюдением (в штаб-квартире $\mathrm{OOH} \mathrm{в} \mathrm{Женеве} \mathrm{на} \mathrm{временной} \mathrm{основе}$ работает Секция по поддержке соблюдения, состоящая из трех плюс минус человек) $)^{31}$.Кроме того, уничтожение запасов химического оружия требует существенных финансовых затрат ${ }^{32}$.В США уничтожение запасов химоружия оценивается в сумму превышающую 30 млрд долларов. Так же ряд стран оказываются за пределами КХО (Ангола, Египет, КНДР, Сирия, Сомали) и КБТО (Ангола, Камерун, Чад, Коморы, Джибути, Эритрея, Гвинея,

\footnotetext{
${ }^{30}$ Кревельд М. Расцвет и упадок государства.С. 425.

${ }^{31}$ Современные глобальные проблемы. С. 57.

32 Зеленов Л.А., Владимиров А.А., Степанов Е.И. Современная глобализация: состояние и перспективы. М., 2010. С. 6.
}

Кирибати, Маршалловы Острова, Мавритания, Микронезия, Мозомбик, Намибия, Науру, Ниуэ, Самоа, Тувалу).

Указанные обстоятельства обусловливают необходимость применения общемировых методов контроля. Например, создание в 2002 году Глобального партнерства по противодействию распространения оружия и материалов массового уничтожения (Великобритания, Германия, Италия, Канада, Россия, США, Франция и Япония), использование международных режимов экспортного контроля ядерного, ракетного, химического и биологического оружия, а также использование различных санкций к государствам, не соблюдающих требования заключенных договоров ${ }^{33}$.Ведутся дополнительные работы по заключению новых соглашений, например: договоры о всеобъемлющем запрещении ядерных испытаний, договоры о запрещении производства оружейных расщепляющихся материалов ${ }^{34}$.

Безопасность связывается не только с конфликтами непосредственно на международной арене. Система нормативного и политико-правового регулирования международного сообщества и составляющих его государств оказывается неспособной и к адекватному сокращению уровня внутренней преступности стран. Согласно пятому обзору $\mathrm{OOH} \mathrm{учтенная} \mathrm{преступность} \mathrm{(конкретное} \mathrm{число}$ правонарушений) увеличилась в период с 1960 по 2000 года в США в 11,8 раза (с 2.0 до 23,7 млн), во Франции - в 5,5 раза (с 0,7 до 3,8 млн), в Германии - в 3, 9 раза (с 1,6 до 6,3 млн), в Англии и Уэльсе - в 1,2 раза (с 4,5 до 5,2 млн), Японии - в 1, 6 раза (с 1,5 до 2,4 млн), России - в 6,2 раза (с 0,4 до 2,5 млн), на территории бывшего СССР - в 6 раз (с 0,7 до 4,2 млн) ${ }^{35}$.

Существующая система международного политико-правового регулирования не разрешает и такую серьезную проблему как международный терроризм ${ }^{36}$. В настоящее время существует около

\footnotetext{
${ }^{33}$ Современные глобальные проблемы. С. 53.

${ }^{34}$ Современные глобальные проблемы. С. 55.

${ }^{35}$ Пряхин В.Ф. Как выжить? Новая идеология для человечества. М., 2008. C. 29.

${ }^{36}$ См.: Эйфари А.К., Манцев В.В. Глобализация и развивающиеся страны (политэкономический аспект). М., 2007. С. 47; Борко Ю.А. Европейский союз: Расширение состоялось. Что дальше? // Европейский союз после расширения: сб. науч. тр. М., 2005.С. 49; Современные глобальные проблемы. С. 38; Русинова В.Н. Проблемы применения международного гуманитарного права и международно-правовых норм о защите
} 
двухсот дефиниций международного терроризма ${ }^{37}$. В общем понимании международный терроризм есть «деятельность и действия, а также содействие им, направленные на изменение политики, целей, и принципов по содержанию международного мира и безопасности, развития дружественных отношений и сотрудничества государств согласно Уставу $\mathrm{OOH}$, а также прав и свобод человека и гражданина, установленных Всеобщей декларацией прав человека и Международным пактом о гражданских и политических правах, влекущие смерть или угрозу ее причинения, иного вида насилия лицам, а также нанесение имущественного или иного ущерба $)^{38}$.

Терроризм как социальное явление и способ политической борьбы качественно изменился с конца XX и начала XXI века. Если ранее основная цель терроризма заключалась в запугивании отдельных лиц или ограниченного числа лиц, то в настоящее время терроризм угрожает тысячам людей и с его применением связывается достижение глобальных политических целей ${ }^{39}$. Современный международный терроризм является следствием катализаторов, которые появляется к настоящему времени все больше и больше. К ним можно отнести легкодоступные транспортные сети и скорость обмена информации, научно-технический прогресс и как следствие - развитие средств массового поражения. Террористическое нападение с применением, например, одного грамма натуральной оспы, закачанного в боеприпас, согласно оценке экспертов, способно привести к гибели от 100 тысяч до 1 млнчеловек ${ }^{40}$. Согласно официальным данным ООН в 1998 году в Интернете существовало менее 20 террористических сайтов, а к 2005 году их число достигало уже

прав человека в ходе борьбы с терроризмом / Международное сообщество и глобализация угроз безопасности. С. 37-55.

37 Терроризм в современном мире / ред. Ю.М. Антонян, В.Л. Шульц. М., 2008. С. 5.

${ }^{38}$ См.: Крылов Б.С. Международное право и проблемы создания правового акта о борьбе с международным терроризмом // Борьба с терроризмом: сб. / ред. В.Н. Кудрявцев. М., 2004. C. 195; Гнатик Е.Н. К проблеме наукоемкого терроризма в глобализующем мире// Глобализация и проблема сохранения культурного многообразия / ред. Ю.В. Хен. М., 2010. С. 77.

${ }^{39}$ Пряхин В.Ф. Как выжить? Новая идеология для человечества. С.33.

${ }^{40}$ Гнатик Е.Н. Указ. соч. С. 82; Более безопасный мир: наша общая ответственность. доклад Группы высокого уровня по угрозам, вызовам и переменам ООН // Безопасность Евразии. 2005. № 1. C. 159. нескольких тысяч ${ }^{41}$. Экстремистами используется не только арсенал высоких технологий, но и наук гуманитарных ${ }^{42}$. Специалисты по психологической подготовке прибегают к использованию суггестивной зависимости кандидатов в террористы, обнаружению развитию комплекса вины, наркотизации ${ }^{43}$.

Наукой не выявлены психологические причины терроризма. Кто из нормальных людей возьмется утверждать, что понимает террориста-смертника?

Ярлыки типа «религиозный фанатик» или «садист-маньяк» свидетельствуют, скорее, о не понимании ${ }^{44}$. Если обычный преступник отрицает социальное всегда частично, террорист - тотально; преступник маскирует преступление, террорист стремится привлечь к нему максимум внимания ${ }^{45}$. Один из выводов, сделанных современными специалистами, состоит в том, что «мотивы террористических действий в основном формируются не в неформальных малых группах, не под влиянием опасных у общеуголовных преступников и в совместном совершении «бытовых преступлений, а в ходе семейного воспитания под влиянием местных этнорелигиозных обычаев и традиций, носящих сугубо пережиточный характер, под влиянием и авторитетных лиц» ${ }^{46}$.

В ракурсе исследования этого феномена интересен следующий факт. Бен Ладен являлся выходцем из богатого рода Саудовской Аравии. Большинство руководителей Глобального исламского джихада Салафи в целом, и АльКайеды, в частности, имеют высшее профессиональное образование, женаты, имеют детей. Среди них нет людей, страдающих психологическими заболеваниями ${ }^{47}$. Согласно исследованиям Марка Сейджмена большинство членов Аль-Кайеды принадлежит к социально

${ }^{41}$ Аннан К. Единство в борьбе с терроризмом: рекомендации по глобальной контртеррорестической стратегии // Безопасность Евразии. 2007. № 1. С. 127.

${ }^{42}$ Гнатик Е.Н. Указ. соч. С. 79.

43 Антонян Ю.М. Личность террориста и вопросы борьбы с терроризмом // Борьба с терроризмом: сб. М., 2004. С. 96-100.

${ }^{44}$ Сумерки глобализации: Настольная книга антиглобалиста / сост. А.Ю. Ашкеров. М., 2004. С. 272.

${ }^{45}$ Сумерки глобализации. С. 273.

${ }^{46}$ Гнатик Е.Н. Указ. соч. С. 80; Антонян Ю.М. Указ. соч. C.96-100.

${ }^{47}$ Куликов В.A. Исламский терроризм или террористический ислам - глобальный вопрос мирового сообщества? / Международное сообщество и глобализация угроз безопасности: сб. науч. докладов. С. 152. 


\section{Национальная безопасность 2(25) • 2013}

обеспеченным слоям населения: $18 \%$ - к высшему классу, более половины - к среднему, одна треть - к низшему. 28,8\% обучались в колледже, $33 \%$ окончили колледж, $9 \%$ имеют ученую степень ${ }^{48}$. Среди членов сети не было обнаружено ни безработных, ни бродяг, пришедших в поисках денег. Более $40 \%$ представляли врачи, юристы, учителя и прочие, $30 \%$ - профессионалы средней квалификации. Средний возраст активистов - около 26 лет $^{49}$. В. Ф. Пряхин справедливо замечает: «Нельзя забывать, что любой мужчина и любая женщина, надевшие на себя пояс шахида, были когда-то просто мальчиком и девочкой, не имевшими каких-либо преступных намерений. Обстоятельства жизни, традиции и идеологическое внушение побудили их встать «на тропу мести», оправдали в их глазах убийство любого человека по определенному расовому, национальному, или социальному признаку, равно как и собственную гибель во имя определенных целей» $\rangle^{50}$.

Борьба с терроризмом - это политическая борьба, борьба идеологий. Ни в каком государстве не должна быть единая и обязательная политическая или другого рода идеология. Для предотвращения террористических актов, влекущих за собой массовые жертвы, необходима глубокая приверженность укреплению систем коллективной безопасности, борьбе с нищетой и терроризмом, уменьшению бед, вызванных войной, борьбе с распространением инфекционных заболеваний и с организованной преступностью ${ }^{51}$. В государстве должен быть абсолютный идеологический плюрализм во всех сферах. Единственным необходимым требованием является необходимость не нарушения прав и свобод граждан другой идейной направленности. Если же государств много, то и понимание прав и свобод граждан является разным. Разумеется, что содержание прав в ЕС, США, большинстве стран СНГ по содержанию совпадает и воплощает достижение гуманизма и либерализма. Но есть идеологии, в которых человек и его права и свободы не являются высшей ценностью, это и есть терроризм, когда человек становится средством.

\footnotetext{
${ }^{48}$ Куликов В.А. Указ. соч. С. 152.

${ }^{49}$ Куликов В.А. Указ. соч. С. 152.

${ }^{50}$ Пряхин В.Ф. Как выжить? Новая идеология для человечества. C. 35-36.

${ }^{51}$ Более безопасный мир: наша общая ответственность. Доклад высокого уровня по угрозам, вызовам и переменам. Организация Объединенных Наций. С. 159.
}

Установление единого, демократического и гуманистического стандарта прав позволит сократить появление радикальных идей. Так как для большинства экстремистских движений наличие большого количества государств и правопорядков является катализатором их роста. В случае если определенная идеология становится не правом, а закрепленной в законе обязанностью, начинает работать правило «убей или будь убитым», что в корне является неверным и противоречит основным человеческим ценностям.

Помимо рассмотренных аспектов безопасности, М. А. Троицкий также указывает на так называемые «нетрадиционные угрозы безопасности», к числу которых помимо климатического влияния на развивающиеся страны он относит распространение наркотических средств и работорговлю. Очагом производства наркотического сырья являлись Афганистан, территория «золотого треугольника» - смежные районы Мьянмы, Таиланда, Лаоса и Вьетнама ${ }^{52}$. В настоящий момент в данных странах производится более 100 тонн опия-сырца. Объем выращенного в Афганистане наркотического сырья в 2007 году достигал 8200 тонн. Количество перевозимых помимо своей воли лиц (в основном женщин и детей) внутри отдельных стран к концу 2000-х гг. достигало несколько сот тысяч.Рассматриваемые факты также свидетельствуют, что проблемы безопасности движутся по возрастающему линейному графику и требуют новых путей решения.

В едином государстве выполнение функции по обеспечению безопасности будет продуктивнее в двух аспектах: во-первых, внутри единого общества будет царить всеобщий мир и демилитаризация, внешние военные конфликты будут полностью отсутствовать, так как будет существовать один суверенитет и государственный аппарат ${ }^{53}$. Второй аспект безопасности будет проявляться в том, что чем больше система, тем она безопасней чувствует себя в отношении других систем. Планетарное государство предоставит широкие возможности для блокирования конфликтов, агрессивных инициатив и других ситуаций, которые могут перерасти в глобальные военные конфликты ${ }^{54}$. Борьба со стихией, катаклизмами, болезням, гипотетически можно

\footnotetext{
${ }^{52}$ Современные глобальные проблемы. С. 162.

${ }_{53}$ Явич Л.С. О философии права на ХХІ век // Правоведение. 2000. № 4. С. $13,14,15$.

${ }^{54}$ Новиков А.А. Указ. соч. С. 45.
} 
предположить и возможность борьбы с другими разумными организмами. Консолидация человечества может быть и единственным средством защиты перед неведомыми угрозами со стороны других цивилизаций населяющих вселенную ${ }^{55}$.

Подводя итог проведенному исследованию можно сделать следующий вывод. Современные международныеи национальные институты показывают несостоятельность в обеспечении безопасности человека, которая усугубляется вовлечением в данный процесс политических и экономических интересов отдельно взятых стран, которые зачастую идут в разрез установленным гуманистическим принципам. В связи с указанными обстоятельствами, устранение данных противоречий возможно только в рамках единой политической организации общества, которая способна исключить противостояние интересов и создать оптимальную схему внутренней и внешней безопасности.

\section{Библиография:}

1. Beetham D., Boyle K. Introducing Democracy: 80 questions and answers. - Policy Press. UNESCO, 1995. - $135 \mathrm{p}$.

2. Гезалов А.А. Трансформация общества в эпоху глобализации: Социально-философский анализ. - М.: Канон+, 2009. - 288 с.

3. Глобальные конфликты нового и новейшего времени: учеб. пособие / под ред. Н.В. Паниной. - М.: МИЭМ, 2005. - 116 с.

4. Глобальные трансформации: Политика, экономика, культура / Д. Хелд, Д. Гольдблатт, Э. Макгрю и др. - М.: Праксис, 2004. - 575 с.

5. Гнатик Е.Н. К проблеме наукоемкого терроризма в глобализующем мире // Глобализация и проблема сохранения культурного многообразия. - М., 2010. - C. 76 - 97.

6. Грохотова В.В. Развитие доктрины «гуманитарной интервенции» в международном праве // Международное сообщество и глобализация угроз безопасности. Ч. 2. Международное сообщество и национальные государства в поиске ответов на новые угрозы безопасности: сб. - В. Новгород, 2008. - С. 25 - 35.

\footnotetext{
${ }^{55}$ Хен Ю.В. Глобализация как фактор эволюции homosapiens // Глобализация и проблема сохранения культурногомногообразия. С. 49.
}

7. Зеленов Л.А. Современная глобализация: состояние и перспективы / Л.А. Зеленов, A.А. Владимиров, Е.И. Степанов. - М.: URSS, 2010. - 298c.

8. Кревельд М. Расцвет и упадок государства. - М.: ИРИСЭН, 2006. - 544c.

9. Куликов В.А. Исламский терроризм или террористический ислам- глобальный вопрос мирового сообщества? / Международное сообщество и глобализация угроз безопасности. Ч.2. Международное сообщество и национальные государства в поиске ответов на новые угрозы безопасности: сб. - В. Новгород, 2008. - C. $146-155$.

10. Население и глобализация / Н.М. Римашевская, В.Ф. Галецкий, А.А. Овсянников и др. - М.: Наука, 2004. - 321 c.

11. Новиков А.А. Планетарное государство - глобальная экономическая и социальная модель. - М.: Спец-Адрес, 2008. - 87 с.

12. Пряхин В.Ф. Как выжить? Новая идеология для человечества. - М.: Весь Мир, 2008. - 142 с.

13. Современные глобальные проблемы: учеб. пособие / В.Г. Барановский, А.Д. Богатуров, И.В. Болгова и др. - М.: Аспект Пресс, 2010. $-348 \mathrm{c}$.

14. Хен Ю.В. Глобализация как фактор эволюции homo sapiens // Глобализация и проблема coхранения культурного многообразия. - М., 2010. $-34-50$.

15. Эйфари А.К. Глобализация и развивающиеся страны (политэкономический аспект) / А.К. Эйфари, В.В. Манцев. - М: РУДН, 2007. -62 c.

\section{References (transliteration):}

1. Beetham D., Boyle K. Introducing Democracy: 80 questions and answers. - Policy Press. UNESCO, 1995. - $135 \mathrm{p}$.

2. Gezalov A.A. Transformatsiya obshchestva $v$ epokhu globalizatsii: Sotsial'no-filosofskiy analiz. - M.: Kanon+, 2009. - 288 s.

3. Global'nye konflikty novogo i noveyshego vremeni: ucheb. posobie / pod red. N.V. Paninoy. - M.: MIEM, 2005. - $116 \mathrm{~s}$.

4. Global'nye transformatsii: Politika, ekonomika, kul'tura / D. Kheld, D. Gol'dblatt, E. Makgryu i dr. - M.: Praksis, 2004. - 575 s. 


\section{Национальная безопасность 2(25) • 2013}

5. Gnatik E.N. K probleme naukoemkogo terrorizma v globalizuyushchem mire // Globalizatsiya i problema sokhraneniya kul'turnogo mnogoobraziya. - M., 2010. - S. 76 - 97.

6. Grokhotova V.V. Razvitie doktriny «gumanitarnoy interventsii» v mezhdunarodnom prave // Mezhdunarodnoe soobshchestvo i globalizatsiya ugroz bezopasnosti. Ch. 2. Mezhdunarodnoe soobshchestvo i natsional'nye gosudarstva $v$ poiske otvetov na novye ugrozy bezopasnosti: sb. - V. Novgorod, 2008. - S. $25-35$.

7. Zelenov L.A. Sovremennaya globalizatsiya: sostoyanie i perspektivy / L.A. Zelenov, A.A. Vladimirov, E.I. Stepanov. - M.: URSS, 2010. - 298c.

8. Krevel'd M. Rastsvet i upadok gosudarstva. - M.: IRISEN, 2006. - 544s.

9. Kulikov V.A. Islamskiy terrorizm ili terroristicheskiy islam - global'nyy vopros mirovogo soobshchestva? / Mezhdunarodnoe soobshchestvo i globalizatsiya ugroz bezopasnosti. Ch.2. Mezhdunarodnoe soobshchestvo i natsional'nye gosudarstva $\mathrm{v}$ poiske otvetov na novye ugrozy bezopasnosti: sb. - V. Novgorod, 2008. - S. $146-155$.

10. Naselenie i globalizatsiya / N.M. Rimashevskaya, V.F. Galetskiy, A.A. Ovsyannikov i dr. - M.: Nauka, 2004. - $321 \mathrm{~s}$.

11. Novikov A.A. Planetarnoe gosudarstvo - global'naya ekonomicheskaya i sotsial'naya model'. - M.: SpetsAdres, 2008. - 87 s.

12. Pryakhin V.F. Kak vyzhit'? Novaya ideologiya dlya chelovechestva. - M.: Ves' Mir, 2008. - 142 s.

13. Sovremennye global'nye problemy: ucheb. posobie / V.G. Baranovskiy, A.D. Bogaturov, I.V. Bolgova i dr. - M.: Aspekt Press, 2010. - 348 s.

14. Khen Yu.V. Globalizatsiya kak faktor evolyutsii homo sapiens // Globalizatsiya i problema sokhraneniya kul'turnogo mnogoobraziya. - M., 2010. $-34-50$.

15. Eyfari A.K. Globalizatsiya i razvivayushchiesya strany (politekonomicheskiy aspekt) / A.K. Eyfari, V.V. Mantsev. - M: RUDN, 2007. - 62 s. 